Bond University

Research Repository

\title{
Quantitative methods of examining the impact of the physical work environment
}

Sander, Elizabeth J; Rafferty, Alannah; Jordan, Peter J.

Published in:

Handbook of Research Methods on the Quality of Working Lives

DOI:

$10.4337 / 9781788118774.00022$

Licence:

Other

Link to output in Bond University research repository.

Recommended citation(APA):

Sander, E. J., Rafferty, A., \& Jordan, P. J. (2019). Quantitative methods of examining the impact of the physical work environment. In D. Wheatley (Ed.), Handbook of Research Methods on the Quality of Working Lives (pp. 207-223). Edward Elgar Publishing. https://doi.org/10.4337/9781788118774.00022

\section{General rights}

Copyright and moral rights for the publications made accessible in the public portal are retained by the authors and/or other copyright owners and it is a condition of accessing publications that users recognise and abide by the legal requirements associated with these rights.

For more information, or if you believe that this document breaches copyright, please contact the Bond University research repository coordinator. 


\title{
Enhancing quality of work life: Examining the impact of the physical work environment
}

\author{
Elizabeth J. Sander \\ Bond University
}

\author{
Alannah E. Rafferty \\ Griffith University \\ Peter J. Jordan \\ Griffith University
}

\begin{abstract}
SUMMARY
Organizations spend significant money to modify the physical work environment to improve employee wellbeing and quality of work life. In this chapter, we examine current methodological approaches used when assessing work environments. We identify important developments that need to occur in research methods used when examining the physical work environment.
\end{abstract}




\section{INTRODUCTION}

Interest in the influence of the physical work environment on employee quality of work life and well-being has a long history. In a letter to Felice Bauer in 1912, the philosopher Franz Kafka lamented, 'time is short, my strength is limited, the office is a horror, the apartment is noisy, and if a pleasant, straightforward life is not possible then one must try to wriggle through by subtle manoeuvres' (Gross, 2002, p. 80). Today, researchers still consider the design of the physical work space and its impact on employees' attitudes, behavior and performance (see Davis et al., 2011; Elsbach \& Pratt, 2007; Taylor \& Spicer, 2007; Zhong \& House, 2012 for reviews). In contrast, less attention has been devoted to the influence of the physical work space on quality of work life. This may be partly attributable to the debate regarding how to define the quality of work life (Martel \& Dupuis, 2004). Seashore (1975) defined quality of work life as employees' subjective perception that they receive a set of beneficial consequences from working life such as income, safety, and the intrinsic satisfaction created by work (Seashore, 1975). Nadler and Lawler (1983) suggest that quality of work life focuses on how work may provide better outcomes for people beyond their performance. Clearly, however, the physical work environment has an impact on employee outcomes and by extension on their quality of work life.

Research reveals that not all modifications to the physical work environment are successful. For example, research by Kim and de Dear (2013) explored the effects of open plan offices, a very popular format for office reconfigurations, and demonstrated the expected increased interaction between employees did not compensate for the loss of privacy experienced in these offices. These findings suggest that increasing numbers of modern workers may well empathize with Kafka's sentiments. Empirical research reveals that modern designs can result in high levels of 
noise producing fatigue, tension headaches and irritation for employees (Ryherd, Waye, Ljungkvist, 2008). Poor acoustics are a significant stressor, and have been shown to elevate heart rates to levels associated with a heart attack (Ising \& Kruppa, 2004; Tiesler \& Oberdorster, 2008). These outcomes are likely to be detrimental to quality of work life and worker wellbeing.

In this chapter, we outline and critique the methodological approaches adopted when studying the physical work environment. We identify recommendations regarding future research methods, with the aim of enhancing researchers' ability to appropriately study and measure, and therefore understand, the ways in which physical work environments influence employees' well-being and quality of work life. Our review reveals that the interdisciplinary nature of the field has resulted in a range of different methodological approaches, often focussing on discrete aspects of the physical work environment, making it hard to develop a consistent body of knowledge relating to the impact of that environment on individuals. One major area of methodological improvement is the need to integrate different, but common, approaches to measurement to allow researchers to investigate ways in which the physical work environment as a whole impacts on individuals, rather than concentrating on the impact of individual physical factors in isolation.

\section{THE PHYSICAL WORK ENVIRONMENT}

The physical work environment in an organization incorporates the material objects and stimuli that people encounter in their day-today work life, as well as the nature and arrangement of these objects and stimuli (Davis, 1984; Davis et al., 2011; Elsbach \& Pratt, 2007; Hedge, 1982; Sundstrom, Bell, Busby, \& Asmus, 1996). The physical work environment differs from the social (i.e. human social structures and norms), urban, and community environment and also may be contrasted with the purely 
natural environment as it encompasses buildings, furnishings, equipment, and ambient conditions such as lighting and air quality (Elsbach \& Pratt, 2007).

An increased focus on the physical work environment has come about partly due to the changing nature of work, which Tannenbaum and his colleagues (2012) argue includes: the ongoing disruption that results from the continual introduction of new technology; changing demographics; the rise of a contingent workforce; and the distribution of work across an ever increasing range of different environments (e.g., hotdesking, co-working spaces). Researchers argue that work is now "boundaryless", in that technology allows work to take place almost anywhere (Ituma \& Simpson, 2010; Saval, 2014; Tremblay, 2003). At the same time, the boundaries of work and ways in which it is enacted are shifting dramatically with the rise of the contingent workforce. Many of these changes have been promoted as increasing flexibility for employees as to where work is conducted, therefore allowing employees to prioritise well-being and work-life balance (Ituma \& Simpson, 2010; Saval, 2016; Tremblay, 2003). As such, the realm of the workplace now extends far beyond the traditional office, to the home, co-working spaces, incubators, meet-up groups and all manner of Oldenburg's (1989) 'third place' such as coffee shops, and other spaces in the public realm. Given this context, it is not surprizing that researchers are now interested in exploring the influence of this broader range of physical work environments on the quality of employee's working lives.

Interest in the influence of the physical work environment on employees is evident in both industry and academia. Many organizations are experimenting with workplace design (Morrow et al., 2012; Spinuzzi, 2012). For example, some organizations have designed their workplaces to resemble the layout of cities, with major avenues, a town square, and a variety of zones to motivate employees to move 
around the office and share information. Further, organizations are beginning to realize the need to balance collaboration spaces with more private areas that provide employees with a place to focus and concentrate (Ferro, 2015). In contrast, other organizations have focused on making work a fun place with the inclusion of gaming spaces and relaxation areas (Turner \& Myerson, 1998). The stated intention of many of these changes is to improve employee's experiences at work and the quality of working life (Davis et al., 2011).

Although there is a proliferation of new locations in which work is being conducted, the "office" - the physical environment where work is conducted - remains extremely relevant, with interest in this setting evident across industry (see Gensler, 2013) and academia (see Davis et al., 2011; Elsbach \& Pratt, 2007 for reviews). Scholars have noted that face-to-face contact still remains central to the coordination of the economy, despite the changes that technology has enabled (Waber, Magnolfi, \& Lindsay, 2014). Billions of dollars are spent annually on office design and implementation and the physical work environment representing the second largest expense behind labor for organizations (McCoy, 2005; Pole \& Mackay, 2009). For example, Apple recently developed a \$US5 billion 60-hectare campus based on Steve Jobs' experiences of the successful physical work environment at Pixar, which has been identified as driving collaboration and innovation (Wilson, 2014).

Research designed to understand the emerging aspects of the physical work environment, however, is limited. In particular, we argue that research lacks both the measures to capture these new aspects of the physical work envornment and also has an insufficient understanding of emerging practical concerns arizing from the modern work environment. An example of these concerns may be reflected in research by Gensler (2013), who found the ability to concentrate in the workplace is becoming a 
significant issue for employees, with only one-quarter of employees reporting satisfaction with the workplace environment.

In this chapter, we outline methodological issues that confront researchers seeking to advance this area of research and we focus on the need to develop new ways of integrating the disparate measures of the physical work environment. To date, both practice and research efforts have adopted a wide range of methods when examining the physical work environment using a wide range of different techniques and measures. In addition, the complex number of interacting factors involved in this field (for example, air quality or spatial layout can impact on physiological, psychological and performance outcomes) mean that researchers often use research methods that only focus on specific aspects of the physical work environment (such as measuring noise levels), rather than trying to assess the environment as a whole through examining the reactions of individuals to the physical work environment. The result is that researchers have not built a cumulative body of knowledge relating to the holistic impact of the physical work environment on broad outcomes such as the quality of work life (Elsbach \& Pratt, 2007).

\section{WELLBEING AND QUALITY OF WORK LIFE}

Mirroring the interest in the physical work environments for both practitioners and managers, there has been a concurrent interest in increasing workplace well-being with a particular focus on quality of work life (e.g., Diener, 2000). Research into wellbeing has a long history with a number of meta analyses of this construct (Faragher, Cass, \& Cooper, 2013; Kuoppala, Lamminpää, Liira, \& Vainio, 2008). Well-being has been linked to a number of antecedents including work factors such as job insecurity (Kühnel, Sonnentag, \& Bledow, 2012), external (family) factors (Allis \& O'Driscoll, 2008) work intensity (Burke, Singh, \& Fiksenbaum, 2010) and stressful events (Burke, 
1994) such as organizational change (Rafferty \& Jimmieson, 2017). Similarly, researchers have discussed the factors that contribute to quality of work life with research establishing that this construct focuses on how work may provide better outcomes for people beyond their performance (Nadler \& Lawler, 1983). Primarily, research on quality of work life has focussed on rewards system, work design and participative problem solving with little consideration of the quality of the physical work environment (Nadler \& Lawler, 1983). Significantly, in the well-being and quality of work life literatures, there was an early focus of researchers in relation to the physical work environment around providing a safe work environment (Walton, 1973). In more recent research, authors have demonstrated a reduced interest in quality of work life. For example, a recent measure of the quality of work life (Sirgy, Efraty, Siegel, \& Lee, 2001) assessed a singleitem measuring the physical work environment ("The janitors and maintenance people we have at work do a good job keeping the place clean and sanitary"). Clearly, the physical work environment has not been a big consideration for quality of work life researchers.

It is now broadly accepted, however, that the physical work environment plays a major role the employee's experiences of work and on this basis is likely to contribute to employees' overall quality of work life. For instance, Bitner (1992) argues that the physical space in which customers and employees interact has a major impact on the quality of social interaction that takes place. Similarly, Klitzman and Stellman (1989) conducted an empirical study and came to the conclusion that the physical work environment had a direct effect on the stress experienced by workers. More recently, Ashkanasy, Ayoko, and Jehn, (2014) argue that the physical work environment has an impact on the emotions experienced by workers. Based on this evidence, researchers should consider aspects of the physical work environment as antecedents of an 
employees' quality of work life. The question that needs to answered, however, is how can research from these two seemingly different paradigms be brought together to address the relationships between the physical work environment and employee quality of worklife? We address this issue below.

\section{THE PHYSICAL WORK ENVIRONMENT}

Research on the physical work environment and quality of work life are not incompatible. For example, the Hawthorne studies (Roethlisberger \& Dixon, 1939) initially focused on the influence of different aspects of the work environment (e.g., lighting levels) on employee productivity, and led to an acknowledgement that employees' social interactions and their emotional responses to these activities are important in the workplace. However, after these studies, research interest in the field waned for several decades until interest was renewed in the late 1970s and 1980s when researchers again turned their attention to the ways in which the physical work environment influenced satisfaction, productivity and communication (see Allen, 1977; Oldham, 1988; Oldham \& Brass, 1979; Sundstrom \& Sundstrom, 1986, for examples). In 1984, Davis suggested that the physical work environment did indeed have an important influence on organizational outcomes and the experience of employees at work. Davis defined the physical work environment as consisting of three dimensions: physical structures such as furnishings and layout, physical stimuli including noise, and symbolic artifacts that communicate status and image (e.g., furnishings, office size). In this section, we first review the major theoretical approaches to the field to begin to highlight the different approaches that have been taken by research. We then examine the specific methodological approaches, and the range of measures utilised in these approaches.

\section{Theoretical approaches to studying the physical work environment}


Research on the physical work environment has been largely constrained by Davis' (1984) conceptualization which focussed on objects and stimuli, resulting in a narrow focus on specific aspects of the physical work environment such as lighting and spacial efficiency. For example, research on the physical work environment has focused on disparate dimensions of the environment including spatial layout (Backhouse \& Drew, 1992; Brennan et al., 2002; Zalesney \& Farace, 1987), building materials (McCoy \& Evans, 2002), decorations (Bringslimark et al., 2009), noise (Yadav, Kim, Cabrera, \& de Dear, 2017; Zaglauer, Drotleff, \& Lieble, 2017), lighting (Zhong \& House, 2012) and opportunities for personalization (Elsbach, 2004). The outcomes of interest in this research has largely been productivity, although interest in the influence of the physical work environment on well-being is increasing (see Yadav et al., 2017; Zaglauer et al., 2017 for examples). Overall, the 'work outcomes' emphasised by Davis seem to have been prioritised over his second stream which was about the 'experience of employees at work'.

There have been several major reviews of the physicial work environment in recent years ( Elsbach \& Pratt, 2007; Taylor \& Spicer, 2007), which have identified additional directions for study. These reviews, along with those of Davis et al. (2011) and Zhong and House (2012) highlight the paradoxes and varying theoretical approaches to research of physical work environments. For example, in their major review of the physicial work environment, Elsbach and Pratt (2007) chose to commence with specific physical characteristics of the work environment itself, such as lighting or partitions. In contrast, Davis et al. (2011) chose to focus on a specific type of physical work environment, open plan offices, perhaps because of the large body of research on this topic, as well as the increasing interest in this area. Finally, Zhong and House (2012) reviewed the literature on implications of the physical work 
environment arising from the four dimensions of the original Hawthorne studies illumination, temperature, cleanliness and distance (Roethlisberger \& Dixon, 1939).

This brief overview highlights the varied approaches to research into the physical work environment. However, there is another way to conceptualize the physical work environment. As seminal studies in the organizational behavior field (see Hackman \& Oldham, 1975; Salancik \& Pfeffer, 1978; Roethlisberger \& Dixon, 1939) have shown, it is the individual employee's subjective reactions to the physical environment, rather than the objective characteristics of the environment that have the most significant effect on attitudes and behavior. For example, studies have shown that giving employees control over aspects of their environment such as lighting, temperature and ventilation, adjustment and location of work, mediates the effects of environmental characteristics that have otherwise been shown to have detrimental effects (Lee \& Brand, 2005). This suggests that the importance of an individual's perceptions and reactions to their physical work environment and their ability to manage and interact with the environment cannot be understated. This interest in employees' subjective experience of the physical work environment has been reflected in measures of this environment. Below, we review the methodlogical approaches that have been adopted when examining the physical work environment.

\section{Methodological approaches to studying the physical work environment}

To date, studies of the impact of the physical work environment have used three approaches; 1) objective measurement of the environment itself (primarily comparing it to standardized benchmarks such as acceptable air quality or noise levels); and 2) self reports that focus on the impact of the subjective impact of the physical environment on psychological outcomes and 3) assessment of physiological outcomes for individuals in specific work environments. The choice of approaches 
selected by a researcher highlights the disciplinary differences betweeen scholars, but also indicates the complexity of study of the physical work environment itself.

An example of the objective measurement approach can be seen in the research of architectural scholars who have utlizied methodologies such as spatial syntax to understand the influence of layouts of the physical work environment on navigation, movement patterns and interaction amongst users (e.g., Turner, Doxa, O'Sullivan, \& Penn, 2001). By constrast, organizational behavior and industrial psychology scholars have been interested in understanding how the physical work environment influences individual reactions such as mood, emotion or identity and primarily use self report surveys to examine these relationships (see Ashkanasy et al., 2014). Finally, an example of the physiological approach is provided by scholars from health disciplines who examine the effects of aspects of the physical work environment by taking objective measures of factors such as noise or air quality and examining the impact of these on specific physiological responses including heart rate variability or cortisol levels (e.g., Magari, Hauser, Schwartz, Williams, Smith, \& Christiani, 2001). We review each of these different approaches below in detail.

\section{Objective measurement of the physical work environment}

The measurement of the physical work environment in the physical sciences focusses on the use of objective data that captures specific dimensions of the workplace (e.g., nits for light, decibles for noise, Square meters per person for spatial comfort; see Horr, Arif, Kaushik, Mazroei, Katafygiotou \& Elsarrag, 2016; Kang, Ou, Ming Mak, 2017 for examples). This research requires the use of technical apparatus and specific skills in interpreting the data that emerges from the research. These approaches are of significant importance to architectural scholars in order to advance the practice of the design of physical work environments to ensure best practice in 
aspects such as access, ventilation, acoustic treatment, navigation and functionality. Although these factors may have implications for the quality of work life, well being and the quality of work life are seldom considered in the physical sciences.

A key challenge for the incorporation of issues around quality of work life in relation to the objective measures of the physical work environment is the need to develop multi-disciplinary research in the field. Architectural approaches to measurement often require specific technical equipment that is not readily available to scholars in other disciplines. As noted by Peterson, Reina, Waldman and Becker, (2015), academic publication requires deep domain expertise and publication in narrow fields, publishing outside of those fields is often not rewarded, reducing the likelihood of multidisciplinary research. However, there is likely to be great benefit that can emerge from multidisciplinary research in this area. For example, organizational behavior experts in psychological reactions and emotions may find the use of spatial syntax methodologies incorporating complex mathematical modelling could provide new insights to this phenomenon. This is already happening to some extent in the health sciences with studies examining factors such as the impact of noise levels on heart rate (Manninen, 1984). While physical science scholars examining the physical work environment generally have not participated in multidisciplinary research, we argue that this type of research may be able to assess broader outcomes and overcome the challenges created by the narrow use of specific methods and measures in this field.

\section{Psychological approaches using self-report}

The second methodlogical approach that is used when studying the physical work environment involves the use of self-report surveys. Specifically, this approach involves asking employees to rate aspects of the work environment (e.g., spatial 
comfort, privacy). For example, a key focus of research in the field is based on postoccupancy evaluation of employees' satisfaction with Indoor Environmental Quality (IEQ) being the major measure used. The IEQ includes dimensions such as indoor air quality, lighting levels, and thermal comfort (Wong, Mui \& Hui, 2008). Employees are generally asked to rate their satisfaction with these elements of the physical work environment (for examples see Kim, Candido, Thomas \& de Dear, 2016; Wong, Mui \& Hui, 2008). Although this self-report methodological approach has been widely adopted, evaluation of the major tool used to assess the work environment, the IEQ, suggests that it has a number of limitations. Scholars suggest that the factors used in this survey fall short in describing the work environment in a way that could allow stakeholders to assess the physical changes that occur in such a move (see Candido, Kim, Dear \& Thomas, 2016; Deuble \& de Dear, 2014 for examples). Further, this type of self-report approach does not consider the psychological reactions and individual preferences of individual employees, or the potential interaction of elements of the physical work environment and subsequent its effects.

There is no question that physical work environments can have powerful effects on individual behavior (Knight \& Baer, 2014), but the mechanisms through which such effects emerge are not clearly established due to the focus of physical science researchers on specific aspects of the work environment like noise and ambient light (Elsbach \& Pratt, 2007; Davis et al., 2011). Oseland (2009) emphasizes the importance of considering aspects such as the variety, layout, purpose and furnishing of spaces to ensure the psychological needs of employees are supported. These reactions are important because employees' cognitive and affective reactions to their work environment have been shown to influence mood, behavior and performance (see Bitner, 1992; Brown \& Robinson, 2011 for examples). Existing 
measures to date, however, have not been used to establish the links between physical attributes of a workplace and psychological states. Some recent research (Sander, Caza, \& Jordan, in press - Reactions to the Physical Work Environment Scale, RPWES) seeks to address this shortcoming by identifying a range of mechanisms through which the physical work environment influences employees' responses. In summary, we identified a number of criticisms of the self-report approach to the study of the physical environment including a failure to consider the psychological reactions and individual preferences of individual employees, or the potential interaction of elements of the physical work environment and subsequent its effects. Although research on the physical work environment using self-report surveys tools are closely aligned with the predominant methodological approach adopted in research on quality of work life, researchers have not yet explored the relationships between the physical work environment and quality of work life. There is real potential to expand the outcomes examined in this research given the complementarity of the methods used.

\section{Physiological Measurement}

A third approach to measurement of the physical work environment focusses on examining employees' physiological reactions to specific dimensions of the physical work environment such as lighting (Veitch, Newsham, Boyce \& Jones, 2008). An example of this is work by Jahncke, Hygge, Halin, Green and Dimberg, (2011), who assessed cortisol levels when considering levels of employee stress and strain in response to noise in the workplace. Although the measurement of physiological reactions in this way is useful to understand the influence of noise in the physical work environment on stress, it may not fully address questions around quality of work life as it fails to take into account associated psychological reactions 
an individual may have to the physical environment as a whole. As such, measurement of the influence of factors such as noise, the introduction of plants, or changes to a user's view or lighting levels on outcomes such as heart-rate variability or cortisol levels, while useful, fail to give researchers an understanding of how the elements of the physical work environment combine to influence quality of work life.

In summary, while we see potential in assessing physiological reactions to the physical work environment, this approach is limited in that it cannot answer important questions about the psychological mechanisms that are associated with these physiological responses. In addition, the use of physiological measures also cannot answer questions around the influence of the physical work environment on quality of work life overall. We suggest that one way forward would be to conduct research that utilizes a variety of types of measures of the physical work environment and links these to a range of outcome measures including physiological and psychological outcomes such as quality of work life. In this way, then, researchers can capitalize on the strengths of the different methods currently in use while building a clearer picture of the broader impact of the physical work environment on a wide array of measures.

\section{Summary of issues around methodological design}

A significant issue in research on the physical work environment relates to the shortfall in the use of multiple methodological approaches to examine holistically the impact of the dimensions of the physical work environment on the reactions of employees to that environment and the quality of work life they experience. For example, as many of the studies on work environments are discipline based, they utilize cross-sectional, self-report surveys or objective measures without considering the whole environment. In addition, very few studies have taken a longitidunal approach to understand the influence of changes to the physical work environment. A 
great deal of research is focussed on post-occupancy evaluation of the physical work environment at single time points, which results in concerns about social desirability bias in responses. Further, the lack of an agreed set of measures, combined with the vast number of elements under consideration (privacy, noise, emotional responses, stress) have resulted in a proliferation of research without a common body of knowledge being developed.

\section{Future directions for research on the physical work environment}

Recent developments have sought to address calls for new methods to assess the ways in which the physical work environment is measured (Davis et al., 2011; Elsbach \& Pratt, 2007). For example, Sander et al. (in press) have proposed a new theoretical framework reflecting the impact of cognitive, affective and relational experiences at work (Grant \& Parker, 2009; Organ \& Near, 1985) on individual's assessment of the physical work environment. In developing their arguments, they show how the physical work environment and its design including layout, use of materials and acoustics, can significantly influence employee well-being (Kim et al., 2016; Nijp, Beckers, van der Voorde, Geurts \& Kompier, 2016), influencing cognitive responses such as tension headaches, affective reactions such as mood and irritation (Ryherd et al., 2008), and physiological effects such as blood pressure and heart rate elevation (Ising \& Kruppa, 2004; Tiesler \& Oberdorster, 2008). This research suggests that there is value in methodological approaches that consider both the dimensions of the physical environment and reactions to that environment. Sanders et al.'s work suggests that psychological reactions can provide the link between concrete features of the environment and employee behaviour. Using this method, future studies can now investigate how particular aspects of the physical work environment shape reactions 
and provide a basis for future work concerning the implications of those psychological reactions.

Other potential methodological developments may involve the use of experimental laboratory manipulation of aspects of the physical work environment. For example, research suggests that employees need to focus on their tasks, and research has shown that workplace environments vary in their ability to support focus, based in part on how much distraction is introduced into the space and how much support the space provides for individuals to adjust the level of distraction they experience (Lee \& Brand, 2005; Veitch \& Gifford, 1996). For example, noisy workplaces disrupt cognitive processing, leading to significant deteriorations in concentration (Banbury \& Berry, 2005). As such, it seems reasonable to suggest that laboratory research could be used to investigate how levels of privacy, cognitive distraction, and environmental control in the physical work environment influence wellbeing and quality of work life.

In conjunction with the RWPES framework (Sander et al., in press), the use of objective measurement of aspects of the physical work environment such as cortisol testing, EEG scans and heart-rate variability can provide more nuanced information to researchers on the influence of specific dimensions of the physical work environment as a whole. Finally, to improve our understanding of the effects of the physical work environment on quality of work life, we propose that researchers include a broader range of outcome variables, rather than only satisfaction, in assessing the effects of the physical work environment. These may include mindfulness (Dane, 2011), thriving (Porath, Spreitzer, Gibson \& Garnett, 2012) and employee engagement (Crawford, LePine \& Rich, 2010), outcomes that been shown to be important factors in employee well-being and quality of working life. The use of physiological methods will allow researchers to gain better insight into the ways in which the physical work environment 
influences internal responses, and how these reponses are linked to outcomes of interest to organizations.

\section{CONCLUSION}

The physical work environment is a vitally important part of organizational life, one that conveys meaning through cues that influence beliefs about oneself, coworkers and the organization (Bitner, 1992). These environmental influences are important, as we know that even subtle environmental cues can influence self-concept and behavior (Alter, 2013; Güsewell \& Ruch, 2012). Unfortunately, despite a significant investment of money and time, our understanding of the ways in which the physical work environment as a whole influences outcomes (including the quality of work life) remains limited (Becker, 2014; Duffy, 2007). In this chapter we have outlined the various theoretical and methodological approaches to research on the physical work environment and recommended additional methods for assessing physical work environment and outlining its links to employee well-being and quality of work life. Our hope is that our arguments are able to advance our knowledge of this important nexus. 


\section{REFERENCES}

Allen, T. J. (1977). Managing the flow of technology: technology transfer and the dissemination of technological information within the $R$ and $D$ organization. Cambridge, MA: MIT.

Allis, P. \& O'Driscoll, M. (2008). Positive effects of nonwork-to-work facilitation on well-being in work, family and personal domains. Journal of Managerial Psychology, 23(3), 273-291.

Alter, A. (2013). Drunk Tank Pink: And Other Unexpected Forces That Shape How We Think, Feel, and Behave. London: Penguin.

Ashkanasy, N. M., Ayoko, O. B., \& Jehn, K. A. (2014). Understanding the physical environment of work and employee behavior: An affective events perspective. Journal of Organizational Behavior, 35(8), 1169-1184.

Backhouse, A. \& Drew, P. (1992). The design implications of social interaction in a workplace setting. Environment and Planning B: Planning and Design, 19, $573-584$.

Banbury, S. P. \& Berry, D. C. (2005). Office noise and employee concentration: identifying causes of disruption and potential improvements. Ergonomics, 48, $25-37$.

Becker, F. D. (2014). When assessing workplace strategy, test, don't guess. Retrieved from http://workplaceinsight.net/wp-content/uploads/2014/06/Work+Place3.pdf

Bitner, M. J. (1992). Servicescapes: the impact of physical surroundings on customers and employees. Journal of Marketing, 56, 37-50. 
Brennan, A., Chugh, J. S. \& Kline, T. (2002). Traditional versus open office design: a longitudinal field study. Environment and Behavior, 34, 279-99.

Bringslimark, T., Hartig, T., \& Patil, G.G. (2009). The psychological benefits of indoor plants: A critical review of the experimental literature. Journal of Environmental Psychology, 29(4), 422-433.

Brown, G. \& Robinson, S. L. (2011). Reactions to territorial infringement. Organization Science, 22, 210-24.

Burke, R. J. (1994). Stressful events, work-family conflict, coping, psychological burnout, and well-being among police officers. Psychological reports, 75(2), 787-800.

Burke, R. J., Singh, P., \& Fiksenbaum, L. (2010). Work intensity: potential antecedents and consequences. Personnel Review, 39(3), 347-360.

Candido, C., Kim, J., de Dear, R., \& Thomas, L. (2016). BOSSA: A multidimensional post-occupancy evaluation tool. Building Research \& Information, 44(2), 214228.

Crawford, E. R., LePine, J. A., \& Rich, B. L. (2010). Linking job demands and resources to employee engagement and burnout: a theoretical extension and meta-analytic test. Journal of applied psychology, 95(5), 834-848.

Dane, E. (2011). Paying attention to mindfulness and its effects on task performance in the workplace. Journal of Management, 37(4), 997-1018.

Davis, T. R. (1984). The influence of the physical environment in offices. Academy of Management Review, 9, 271-83.

Davis, M. C., Leach, D. J. \& Clegg, C. W. (2011). The physical environment of the office: contemporary and emerging issues. In Hodgkinson, G. P. and Ford, J. K. 
(Eds), International Review of Industrial and Organizational Psychology. .

Chichester, UK: Wiley, 26, 193-235.

Diener, E. (2000). Subjective well-being: The science of happiness and a proposal for a national index. American Psychologist, 55(1), 34-43.

Deuble, M. P. \& de Dear, R. J. (2014). Is it hot in here or is it just me? Validating the post-occupancy evaluation. Intelligent Buildings International, 6(2), 112-134.

Duffy, F. (2007). The death and life of the urban office. In R. Burdett \& D. Sudjic (Eds), The endless city: The urban age project by the London School of Economics (pp. 328-339). London: Phaidon Press.

Elsbach, K. D. (2004). Interpreting workplace identities: the role of office décor. Journal of Organizational Behavior, 25(1), 99-128.

Elsbach, K. D. \& Pratt, M. G. (2007). The physical environment in organizations. The Academy of Management Annals, 1, 181-224.

Faragher, E. B., Cass, M., \& Cooper, C. L. (2013). The relationship between job satisfaction and health: a meta-analysis. In Cooper, C. (Ed.).From Stress to Wellbeing Volume 1 (pp. 254-271). Palgrave Macmillan, London.

Ferro, S. (2015) Six major design trends shaping city life in 2015. Retrieved from http://www.fastcodesign.com/3040823/6-major-design-trends-shaping-city-lifein-2015

Gensler. (2013). 2013 U.S. Workplace Survey. Available at: http://www.gensler.com/uploads/document/337/file/2013_US_Workplace_Surv ey_07_15_2013.pdf

Grant, A. M. \& Parker, S. K. (2009). Redesigning work design theories: the rise of relational and proactive perspectives. The Academy of Management Annals, $\mathbf{3}$, $317-75$. 
Gross, R. V. (2002). Kafka's short fiction. In J. Preece (Ed.), The Cambridge companion to Kafka (pp. 80). Cambridge, Cambridge University Press.

Güsewell, A. \& Ruch, W. (2012). Are there multiple channels through which we connect with beauty and excellence? The Journal of Positive Psychology, 7, 516-29.

Hackman, J. R. \& Oldham, G. R. (1976). Motivation through the design of work: Test of a theory. Organizational Behavior and Human Performance, 16(2), 250-279.

Hedge, A. (1982). The open-plan office: a systematic investigation of employee reactions to their work environment. Environment and Behavior, 14, 519-42.

Horr, Y., Arif, M., Kaushik, A., Mazroei, A., Katafygiotou, M., \& Elsarrag, E. (2016). Occupant productivity and office indoor environment quality: A review of the literature. Building and Environment, 105, 369-389.

Ising, H. \& Kruppa, B. (2004). Health effects caused by noise: evidence in the literature from the past 25 years. Noise \& Health, 6(22), 5-13.

Ituma, A. \& Simpson, R. (2009). The boundaryless' career and career boundaries: Applying an institutionalist perspective to ICT workers in the context of Nigeria. Human Relations, 62(5), 727-761.

Jahncke, H., Hygge, S., Halin, N., Green, A. M., \& Dimberg, K. (2011). Open-plan office noise: Cognitive performance and restoration. Journal of Environmental Psychology, 31(4), 373-382.

Kang, S., Ou, D., \& Mak, C. M. (2017). The impact of indoor environmental quality on work productivity in university open-plan research offices. Building and Environment, 124, 78-89.

Kim, J., Candido, C., Thomas, L., \& de Dear, R. (2016). Desk ownership in the workplace: The effect of non-territorial working on employee workplace 
satisfaction, perceived productivity and health. Building and Environment, 103, 203-214.

Kim, J. \& de Dear, R. (2013). Workspace satisfaction: The privacy-communication trade-off in open-plan offices. Journal of Environmental Psychology, 36, 18-26.

Klitzman, S. \& Stellman, J. M. (1989). The impact of the physical environment on the psychological well-being of office workers. Social Science \& Medicine, 29(6), 733-742.

Knight, A. P. \& Baer, M. (2014). Get up, stand up: The effects of a non-sedentary workspace on information elaboration and group performance. Social Psychological and Personality Science, 5, 910-17.

Kuoppala, J., Lamminpää, A., Liira, J., \& Vainio, H. (2008). Leadership, job wellbeing, and health effects - a systematic review and a meta-analysis. Journal of Occupational and Environmental Medicine, 50(8), 904-915.

Kühnel, J., Sonnentag, S., \& Bledow, R. (2012). Resources and time pressure as daylevel antecedents of work engagement. Journal of Occupational and Organizational Psychology, 85(1), 181-198.

Lee, S. Y. \& Brand, J. L. (2005). Effects of control over office workspace on perceptions of the work environment and work outcomes. Journal of Environmental Psychology, 25, 323-33.

Magari, S. R., Hauser, R., Schwartz, J., Williams, P. L., Smith, T. J., \& Christiani, D. C. (2001). Association of heart rate variability with occupational and environmental exposure to particulate air pollution. Circulation, 104(9), 986991.

Manninen, O. (1984). Hearing threshold and heart rate in men after repeated exposure to dynamic muscle work, sinusoidal vs stochastic whole body vibration and 
stable broadband noise. International Archives of Occupational and Environmental Health, 54(1), 19-32.

Martel, J. P., \& Dupuis, G. (2006). Quality of Work Life: Theoretical and Methodological Problems, and Presentation of a New Model and Measuring Instrument. Social Indicators Research, 77(2), 333-368.

McCoy, J. M. (2005). Linking the physical work environment to creative context. The Journal of Creative Behavior, 39, 167-89.

McCoy, J. M. \& Evans, G. W. (2002). The potential role of the physical environment in fostering creativity. Creativity Research Journal, 14, 409-26.

Morgeson, F. P., Dierdorff, E. C., \& Hmurovic, J. L. (2010). Work design in situ: Understanding the role of occupational and organizational context. Journal of Organizational Behavior, 31(2-3), 351-360.

Morrow, P. C., McElroy, J. C. \& Scheibe, K. P. (2012). Influencing organizational commitment through office redesign. Journal of Vocational Behavior, 81, 99111.

Nadler, D. A. \& Lawler III, E. E. (1983). Quality of work life: perspectives and directions. Organizational Dynamics, 11(3), 20-30.

Nijp, H. H., Beckers, D. G., van de Voorde, K., Geurts, S. A., \& Kompier, M. A. (2016). Effects of new ways of working on work hours and work location, health and job-related outcomes. Chronobiology International, 33(6), 604-618. Oldenburg, R. (1989). The great good places: Cafes, coffee shops, community centers, beauty parlors, general stores, bars, hangouts and how they get you through the day. New York: Paragon House. 
Oldham, G. R. (1988). Effects of changes in workspace partitions and spatial density on employee reactions: A quasi-experiment. Journal of Applied Psychology, 73(2), 253-258.

Oldham, G. R. \& Brass, D. J. (1979). Employee reactions to an open-plan office: A naturally occurring quasi-experiment. Administrative Science Quarterly, 24, 267-284.

Organ, D. W. \& Near, J. P. (1985). Cognition vs affect in measures of job satisfaction. International Journal of Psychology, 20, 241-53.

Oseland, N. (2009). The impact of psychological needs on office design. Journal of Corporate Real Estate, 11(4), 244-254.

Peterson, S. J., Reina, C. S., Waldman, D. A., \& Becker, W. J. (2015). Using physiological methods to study emotions in organizations. In Härtel, C. E., Zerbe, W. J., \& Ashkanasy, N. M. (Eds). New Ways of Studying Emotions in Organizations. (pp. 1-27). Emerald Group Publishing Limited.

Pole, S. \& Mackay, D. (2009). Occupancy cost reduction: Proven techniques for these tough times. The Leader, 8(4), 12-17.

Porath, C., Spreitzer, G., Gibson, C., \& Garnett, F. G. (2012). Thriving at work: Toward its measurement, construct validation, and theoretical refinement. Journal of Organizational Behavior, 33(2), 250-275.

Rafferty, A., \& Jimmieson, N. L. (2017). Subjective perceptions of organizational change and employee resistance to change: Direct and mediated relationships with employee well-being. British Journal of Management, 28(2), 248-264.

Roethlisberger, F. J. \& Dickson, W. J. (1939). Management and the Worker: An Account of a Research Program Conducted by the Western Electric Co., Hawthorne Works, Chicago. Cambridge, MA: Harvard University Press. 
Ryherd, E. E., Waye, K. P., \& Ljungkvist, L. (2008). Characterizing noise and perceived work environment in a neurological intensive care unit. The Journal of the Acoustical Society of America, 123(2), 747-756.

Salancik, G. R. \& Pfeffer, J. (1978). A social information processing approach to job attitudes and task design. Administrative Science Quarterly, 23(2), 224-253.

Sander, E.J., Caza, A. \& Jordan, P.J. (in press). Psychological Perceptions Matter: Developing the Reactions to the Physical Work Environment Scale, Building and Environment

Saval, N. (2014). Cubed: A secret history of the workplace. New York: Doubleday. Seashore, S. E. (1975). Defining and measuring the quality of working life. In L. E. Davis \& A. B. Cherns (Eds.), The quality of working life (pp. 105-118). New York: The Free Press. .

Sirgy, M. J., Efraty, D., Siegel, P., \& Lee, D. J. (2001). A new measure of quality of work life (QWL) based on need satisfaction and spillover theories. Social Indicators Research, 55(3), 241-302.

Spinuzzi, C. (2012). Working alone together coworking as emergent collaborative activity. Journal of Business and Technical Communication, 26, 399-441.

Sundstrom, E., Bell, P. A., Busby, P. L. \& Asmus, C. (1996). Environmental Psychology 1989-1994. Annual Review of Psychology, 47, 485-512.

Sundstrom, E. \& Sundstrom, M. G. (1986). Work Places: The Psychology of the Physical Environment in Offices and factories. Cambridge: Cambridge University Press.

Tannenbaum, S.I., Mathieu, J.E., Salas, E., \& Cohen, D. (2012). Teams are changing: Are research and practice evolving fast enough? Industrial and Organizational Psychology, 5(1), 2-24. 
Taylor, S. \& Spicer, A. (2007). Time for space: A narrative review of research on organizational spaces. International Journal of Management Reviews, 9(4), 325346.

Tiesler, G. \& Oberdörster, M. (2008). Noise - a stressor? Acoustic ergonomics of schools. Building Acoustics, 15(3), 249-261.

Tremblay, D.G. (2003). New types of careers in the knowledge economy? Networks and boundaryless jobs as a career strategy in the ICT and multimedia sector. Retrieved from https://www.teluq.ca/chaireecosavoir/pdf/NRC03-12A.pdf

Turner, A., Doxa, M., O'sullivan, D., \& Penn, A. (2001). From isovists to visibility graphs: a methodology for the analysis of architectural space. Environment and Planning B: Planning and Design, 28(1), 103-121.

Turner, G., \& Myerson, J. (1998). New workspace, new culture: office design as a catalyst for change. Hampshire, UK: Gower Publishing.

Veitch, J. A. \& Gifford, R. (1996). Choice, perceived control, and performance decrements in the physical environment. Journal of Environmental Psychology, 16, 269-76.

Waber, B., Magnolfi, J., \& Lindsay, G. (2014). Workspaces that move people. Harvard Business Review, 92(10), 68-77.

Walton, R. E. (1973). Quality of working life: what is it. Sloan Management Review, 15(1), 11-21.

Wilson, M. (2014). Norman Foster on designing Apple's \$5 billion “spaceship” campus. Retrieved from https://www.fastcodesign.com/3029477/norman-fosteron-designing-apples-5-billion-spaceship-campus 
Wong, L. T., Mui, K. W., \& Hui, P. S. (2008). A multivariate-logistic model for acceptance of indoor environmental quality (IEQ) in offices. Building and Environment, 43(1), 1-6.

Yadav, M., Kim, J., Cabrera, D., \& De Dear, R. (2017). Auditory distraction in openplan office environments: The effect of multi-talker acoustics. Applied Acoustics, 126, 68-80.

Zaglauer, M., Drotleff, H., \& Liebl, A. (2017). Background babble in open-plan offices: A natural masker of disruptive speech?. Applied Acoustics, 118, 1-7.

Zalesny, M. D., \& Farace, R. V. (1987). Traditional versus open offices: A comparison of sociotechnical, social relations, and symbolic meaning perspectives. Academy of Management Journal, 30(2), 240-259.

Zhong, C. B. \& House, J. (2012). Hawthorne revisited: organizational implications of the physical work environment. Research in Organizational Behavior, 32, 3-22. 


\section{ANNOTATED FURTHER READING}

Up to 3 references for further reading with a short 1 sentence annotation.

Davis, M. C., Leach, D. J. \& Clegg, C. W. (2011). The physical environment of the office: contemporary and emerging issues. In Hodgkinson, G. P. and Ford, J. K. (Eds), International Review of Industrial and Organizational Psychology. . Chichester, UK: Wiley, 26, 193-235.

This article give an overview of issues around the physical work environment and the findings can be linked to the quality of work life.

Lee, S. Y. \& Brand, J. L. (2005). Effects of control over office workspace on perceptions of the work environment and work outcomes. Journal of Environmental Psychology, 25, $323-33$

An early paper that identifies how control over physical space can effect the outcomes of employees at work

Sander, E.J., Caza, A. \& Jordan, P.J. (in press). Psychological Perceptions Matter:

Developing the Reactions to the Physical Work Environment Scale, Building and

\section{Environment}

This article develops a new measure of the physical work environment that may be useful in assessing quality of work life. 